\title{
Educational responses to immigrant students in Madrid
}

\author{
Cristina Goenechea Permisán* and José Antonio García \\ Fernández \\ University Complutense of Madrid
}

\begin{abstract}
During the last few years, changes in the Spanish educational system have had a far reaching impact. Several factors have been critical: (1) the progressive decentralization of education by the government, now a responsibility of regional governments; (2) the extension of compulsory education to the age of 16; and finally (3) the increase in the number of immigrant students, which has significantly added to the existing cultural diversity. The enrolment of immigrant students in Spanish schools is a relatively recent phenomenon (starting 15 years ago) when compared with other European countries. Madrid is the region in Spain with the largest number of students. As most of these students were born outside of Spain, we cannot yet speak of a second generation. The research described here investigated how the educational system in Madrid confronted the challenge of an increasing number of immigrant students. The institutional response was the Madrid Regional Government's Compensatory Education Regional Plan. This encompasses several measures, which are described here. After a critical analysis of educational policies pertaining to immigrant pupils, the paper suggests ways of overcoming a purely compensatory approach. Intercultural education plays a key role is such considerations.
\end{abstract}

\section{Introduction}

The number of immigrant pupils in Spain has grown significantly during recent decades and especially since the beginning of the 1990s. During the 2005-2006 academic year, there were more than half a million immigrant students ${ }^{1}$ in Spain. This represents $7.4 \%$ of the total number of young people enrolled in education. Spain's educational system can now be considered truly multicultural. One does need to keep in mind that this is a relatively new phenomenon. For example, some ten years ago there were approximately 50,000 immigrant students in Spanish classrooms. Figure 1 shows this increase.

\footnotetext{
*University Complutense of Madrid, c/ Rector Royo Villanova, s/n, 28040 Madrid, Spain. Email: cgoenechea@edu.ucm.es
}

ISSN 1467-5986 (print)/ISSN 1469-8439 (online)/07/030207-07 


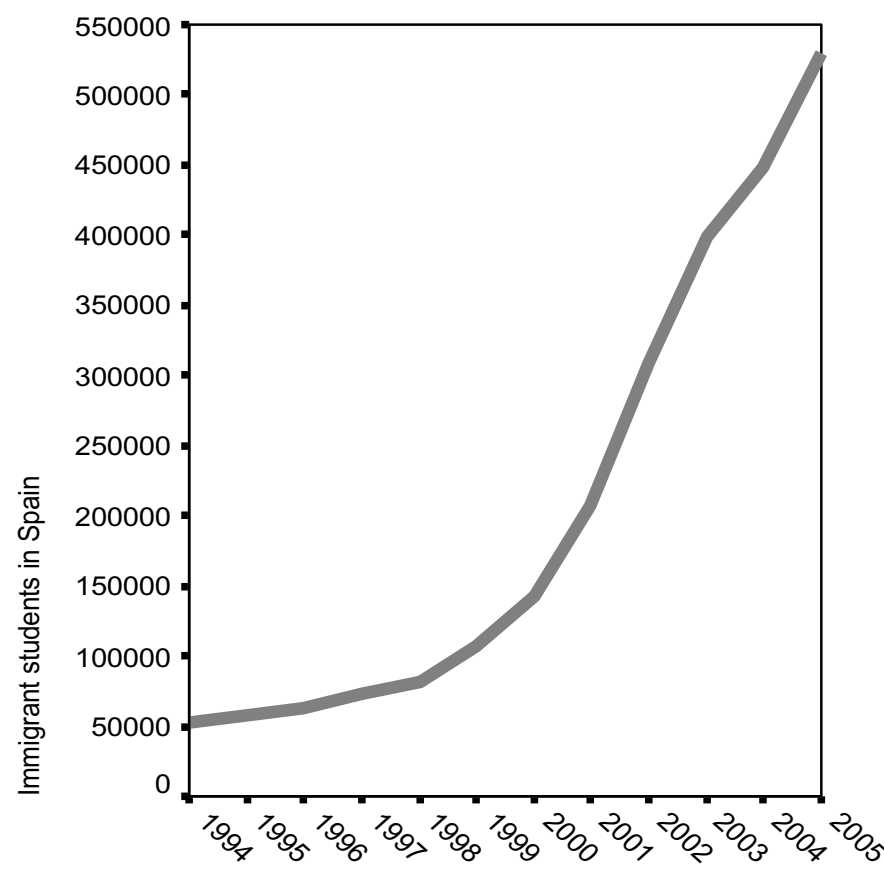

Figure 1. Number of immigrant students in Spain ${ }^{2}$

As in many other countries, immigration is not evenly distributed in geographic terms. There are considerable differences between the seventeen Autonomous Regions of Spain. Almost $45 \%$ of all immigrant students attend school in Madrid or Catalonia. Madrid is the region with the largest number and percentage of immigrant students: 107,224 in 2005-2006 (see Figure 2). ${ }^{3}$ This represents $11.4 \%$ of the total student population. Fewer immigrant students are found elsewhere. For example, in Galicia, they represent only $2 \%$ of the total number of students.

Another distinct feature of the Spanish administrative landscape is its decentralized nature. The different Autonomous Regions have assumed powers that were once the responsibility of the central government - this also applies to educational provisions. Though the most important educational policies and laws are made at the state level, most are passed and implemented by the autonomous administrations. One of the consequences is that the educational services provided to immigrant pupils varies per region.

Generally speaking, differences also exist between Madrid and Spain with respect to the origin of immigrant students (see Figure 3). Both for Spain as a whole and for Madrid, South Americans are the largest immigrant group. The second largest group are European immigrants. The third largest group (though growing in proportion and often the focus of media reports) are Africans.

It is important to reiterate that, at the moment, most immigrant students in Spain are first generation, a situation somewhat different from most other European countries. Though most immigrant students in Spain and Madrid attend public 
Educational responses to immigrant students in Madrid 209

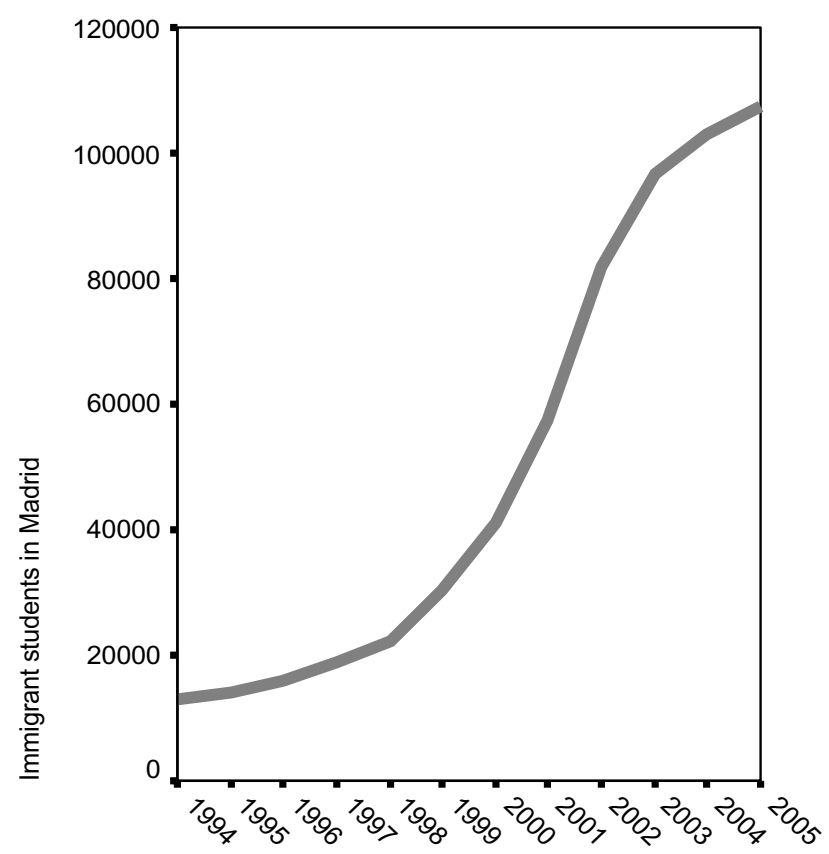

Figure 2. Number of immigrant students in Madrid

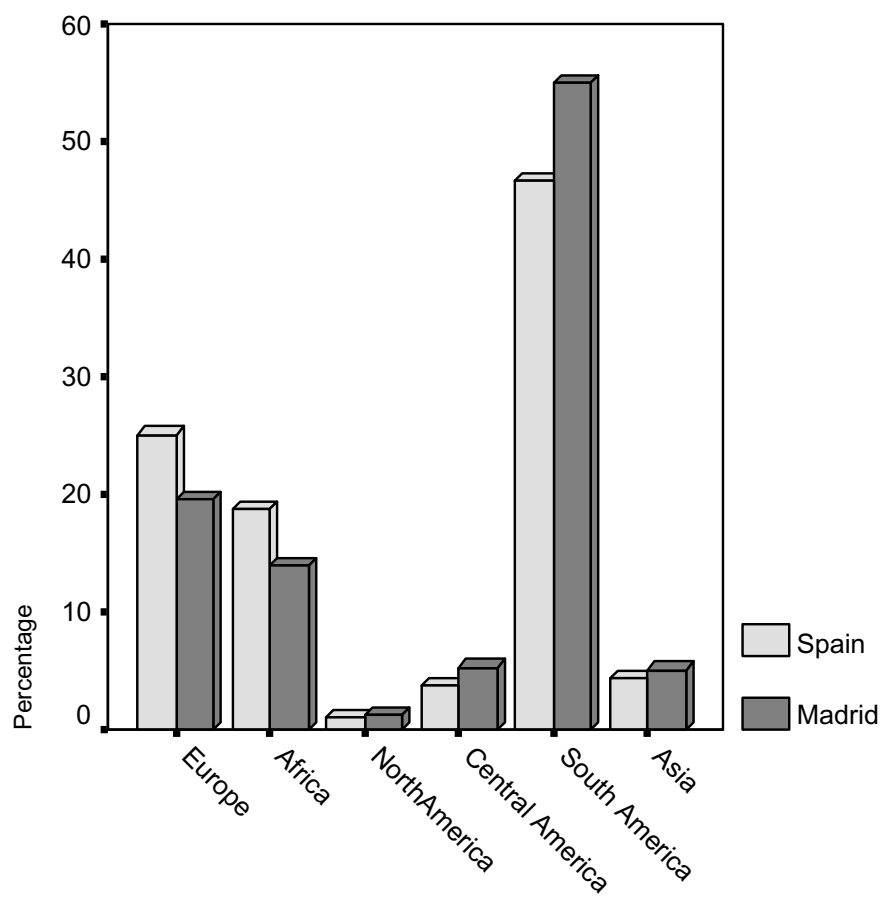

Figure 3. Origin of immigrant students in Spain and Madrid 
educational bodies, the percentage is somewhat lower in Madrid: $81 \%$ of immigrant students in Spain vs. $74.4 \%$ in Madrid.

\section{Educating immigrant students in the Madrid area}

Let us examine how local authorities in Madrid and the surrounding area have responded to the new diversity to be found in the region. The Madrid Regional Government's (Comunidad de Madrid) institutional response has been the creation of the Compensatory Education Regional Plan. This has been in place since 1999, and encompasses several measures:

(a) transitional classrooms

(b) educational compensatory classrooms

(c) maintenance of mother tongue and culture programmes

(d) itinerant support service

(e) external compensation services, outside the school timetable

(f) interpreter and translator services, to provide communication between schools and those families that do not speak Spanish.

\section{'Transitional classrooms' (aulas de enlace), within the 'Welcome Schools' programme}

'Welcome Schools' are defined as educational institutions that aim to provide intercultural education for all students. Knowledge, respect and understanding of 'others', promoting sociocultural education and developing positive attitudes towards other cultures are key components of this approach.

Transitional classrooms are the main resource used to assist immigrant students (at both the primary and secondary levels) who live in Madrid. Specifically, these classrooms cater to immigrant pupils who cannot speak Spanish or cannot participate in regular classes because of their limited knowledge. Students stay in these classrooms for a maximum of six months. They also attend several lessons each day in an 'ordinary classroom'. This is done to speed up integration and also to avoid such transitional classrooms from creating a separate sub-population in the school. The time that immigrant students spend in a regular Spanish classroom increases over time as their language skills improve. The promotion of self-esteem, confidence building and the development of socio-emotional roots are all educational aims in the transitional classrooms.

The methodology used in these classrooms is open and flexible, and importance is attached to cooperative learning. All students in the transitional classroom have a 'tutor-student' from the Spanish 'regular' group. This has been done to avoid isolation and promote integration. Moreover, students have a 'student-monitor', who comes from the student's own country, and speaks his/her own language. The student couples meet twice a week to share their experiences.

The transitional classrooms programme started during the 2002-2003 academic year. A year later, there were 186 transitional classrooms throughout the Madrid 
area. Forty-two per cent of them were located in 'centros concertados' (semi-private schools ${ }^{4}$ ). This is surprising because only $25.6 \%$ of immigrants study in such institutions.

Each transitional classroom has a maximum of 12 students, with one or two teachers. Teachers are specialists in teaching Spanish or have extensive experience with immigrant students. These teachers belong to the Psychological Guidance Department in the school. Children can only attend transitional classrooms if their families agree. After six months in a transitional classroom, the student is integrated into the regular lessons of the school. This can take place in the same school or another school, depending on placement possibilities.

\section{Educational compensatory classrooms}

Educational compensatory classrooms (ACEs) are aimed at students between the ages of 14 and 16, who are at risk of leaving school due to family or social problems, and who might not otherwise obtain a secondary school diploma. Furthermore, the knowledge of these students must be two years behind the norm for their age, and they must have negative feelings towards formal schooling and have serious difficulties adjusting to formal educational settings.

There are 14 ACEs in the five zones under the auspices of the Madrid Regional Government. In each of these, students can select a variety of vocational courses such as electrical engineering, cooking, hairdressing, gardening, carpentry, etc.

\section{Maintenance of mother tongue and culture programmes}

These take place in line with agreements between the Spanish government and the governments of Portugal and Morocco. The students attend classes that focus on the culture of their country of origin, and they also receive instruction in their mother tongue.

\section{Itinerant support service for immigrant students}

This service only exists in those institutions that do not have the above-mentioned services. Teachers in these classrooms advise schools with a limited number of immigrant students and also teach Spanish to these students.

\section{External compensation services, outside the school timetable.}

The aim of the external compensation services is to develop socio-educational spaces for cooperation with the local community in schools, and to improve the educational process of the students in a disadvantaged situation.

The activities take place in cooperation with other state institutions and with non profit organizations, outside the official timetable. They work on, for example, the use of new technologies, social skills or extra help with schoolwork. Also, there are 
'open classrooms' (for the entire local community) that focus on theatre, sport, music and dance.

\section{Interpreter and translator services}

These services provide communication between schools and those families who speak a limited amount of Spanish. They presently work in 30 languages.

\section{Final considerations}

This brief overview focused on an ambitious and recent set of measures. Time and solid evaluation will tell to what extent they have been effective. In the meantime, the author would like to voice some critical remarks about the way immigrant students in Madrid are presently being treated.

(a) The main criticism is the inclusion of all these measures within the framework of compensatory education. This kind of education is aimed at compensating for a perceived handicap in the student. In the authors' opinion, this approach contains the risk of blaming the victim, instead of locating the responsibility for the problem within the educational system, which is unable to provide a suitable answer to diversity. This model is not compatible with intercultural education, because it does not appreciate the culture of the immigrant or ask for any change to mainstream educational institutions or society. It is the authors' view that 'intercultural education is a global and transforming approach that implies and affects all and each one of the members of the society. In this sense, it is far from any kind of compensatory approach and of course it is very different from immigrant or minority education' (Grañeras et al., 2006)

(b) Changes affecting the whole educational system are not being proposed. Specific measures are proposed to give a response to a specific problem. These measures are necessary but not enough to respond to diversity.

(c) There is a certain degree of terminological confusion in Spain. For example, much of the time one finds assimilationist practices when the goal is supposedly integration. A profound debate within the educational community is both urgent and necessary about the preferred educational model and the type of society that we would like to live in.

(d) There is a risk of labelling schools with transitional classrooms as 'schools for immigrants', and this can lead native Spanish parents to remove their children from these schools.

(e) The self-image of those who attend these classrooms needs to be considered. Do they consider themselves to be different (or inferior)? Are they considered to be different by other students?

(f) The distribution of the transitional classrooms does not seem to be appropriate$42 \%$ of these classes are in semi-private institutions, but only $25.6 \%$ of immigrants attend these. 
(g) In the authors' view, the best way for immigrant students to learn Spanish is to integrate them into a mainstream group instead of separating them and placing them into special groups.

(h) There is an obvious lack of training for teachers, who generally have not been trained to work with such children. It is an urgent matter to improve both initial and ongoing teacher training in order to qualify them to work with intercultural educational materials and methodologies.

Finally, some measures included in the recent Educational Law in Spain (4 May 2006), such as a reduction in the number of pupils per class, improvements in teacher training, the equal distribution of the students with special needs between public and private schools, the increase in the autonomy of schools, etc. may contribute to reform education in a positive way.

\section{Notes}

1. 'Immigrant pupils' are defined as those that do not have Spanish citizenship. All data pertaining to Spain are taken from the document Education statistics in Spain, 2006-2007'. Available online from the web site of the Ministry of Education at: http://www.mecd.es.

2. Data from Educational statistics in Madrid 2006-2007. Provisional data. Available online at: http://www.madrid.org

3. 'Centros concertados': semi-private schools with special status, as they receive some funding from the State or the Autonomous Community.

\section{Notes on contributors}

Cristina Goenechea has taught since 2004 in the Faculty of Education at the University Complutense, in Madrid (Spain). She has published extensively in Spanish academic journals, covering different topics in intercultural education. José Antonio García Fernández is professor at Universidad Complutense de Madrid (Spain). $\mathrm{He}$ is also the head of the Didactics and School Organization Department and the Coordinator of Investigation Group about Intercultural Education in the Faculty of Education.

\section{References}

Grañeras, M., Mata, P., Ruiz de Lobera, M., Tuts, M. \& Vale-Vasconcelos, P. (2006) CREADE: resource information for cultural diversity in education, Intercultural Education, 17(5), 485-497. 